\section{Knowledge, attitude and practice of type 2 diabetic patients regarding obesity: study in a tertiary care hospital in Bangladesh}

\author{
Farzana Saleh, ${ }^{1}$ Shirin Jahan Mumu, ${ }^{2}$ \\ Ferdous Ara, ${ }^{1}$ Liaquat Ali, ${ }^{3}$ \\ Sharmin Hossain, ${ }^{4}$ Kazi Rumana Ahmed ${ }^{4}$ \\ 1Department of Community Nutrition, \\ Bangladesh Institute of Health Sciences \\ (BIHS); '2Department of Epidemiology, \\ Bangladesh Institute of Health Sciences \\ (BIHS); ${ }^{3}$ Department of Biochemistry and \\ Cell Biology, Bangladesh Institute of \\ Health Sciences (BIHS); ${ }^{4}$ Department of \\ Health Education and Health Promotion, \\ Bangladesh Institute of Health Sciences \\ (BIHS)
}

\section{Abstract}

Prevention and management of obesity largely depends on patient motivation and education and these, in turn, can be greatly facilitated by adequate baseline data on the knowledge, attitude and practice (KAP) of patients. The aim of this study is to assess KAP on obesity among Bangladeshi type 2 diabetics. Under a cross-sectional design 160 type 2 diabetics were selected from outpatient department of Bangladesh Institute of Research and Rehabilitation in Diabetes, Endocrine \& Metabolic Disorders. A standard questionnaire was constructed in local language and interview was administrated. Age and body mass index (BMI) of the respondents were $45.17 \pm 5.68$ years and $25.6 \pm 4 \mathrm{~kg} / \mathrm{m}^{2}$ respectively. Among them $45 \%$ were male, $38 \%$ had primary education, $25 \%$ belonged to normal weight, 1/2 of them were overweight and rest were obese. KAP score of the respondents was [mean $\pm \mathrm{SD}(\%)] \quad 60.03 \pm 13.82,79.30 \pm 8.27$, $55.50 \pm 19.21$ respectively. Majority were unaware about ideal body weight, energy requirement and the weight measurement techniques. A substantial proportion of the respondents considered fast food, soft drinks, mayonnaise as healthier food. Majority of them positively agreed on willingness to follow proper diet, maintaining ideal body weight, dietary management and exercise. More than half of the normal weight and overweight respondents did exercise $>45 \mathrm{~min}$, while $1 / 3$ obese did not do exercise (35\%). KAP score were significantly associated with respondents' level of education $(\mathrm{P}=0.0001, \mathrm{P}=0.007$, $\mathrm{P}=0.05$ respectively) practice score was significantly associated with sex $(\mathrm{P}=0.0001)$, occu- pation $(\mathrm{P}=0.003)$ and $\mathrm{BMI}(\mathrm{P}=0.0001)$. There is a need for increased effort towards developing and making education programs focusing on empowering the persons to transform their knowledge and attitude into practice.

\section{Introduction}

Obesity is becoming a major public health problem all over the world due to its link with diabetes, hypertension and other disorders related to metabolic syndrome. Developing countries are also increasingly vulnerable to the worldwide epidemic of obesity, which affects all segments of the population and appear to be at greater risk of the diseases associated with overweight and obesity. ${ }^{1}$ Several studies, conducted in urbanizing rural community of Bangladesh, showed that there is a significant association between higher body mass index (BMI) and incidence of diabetes mellitus. ${ }^{2-4}$ In Bangladesh, social and environmental changes are occurring rapidly, resulting in lifestyles that incorporate the use of high energy density diets and reduced physical activity which might have contributed to the increasing prevalence of diabetes. 5,6 Moreover, complications of diabetes also increase among obese diabetic patients. However, changes in lifestyle that lead to weight loss reduce the incidence of diabetes and onset of its complications. ${ }^{7,8}$ Management of obesity largely depends on patient motivation and education. These, in turn, can be greatly facilitated by adequate baseline data on the knowledge, attitude and practice (KAP) of patients. Knowledge is influenced by socioeconomic and cultural factors, attitude, readiness to learn, family support and barriers to care. ${ }^{9}$ Since socioeconomic and cultural perspectives are strong determinants of KAP, ${ }^{10}$ these studies need to be conducted in specific communities. Very few studies have been performed on these issues particularly in developing country like Bangladesh. The aim of the present study was to assess KAP on obesity among Bangladeshi type 2 diabetic patients.

\section{Materials and Methods}

Under a cross-sectional design 160 type 2 diabetic patients were selected purposively from the outpatient department (OPD) of BIRDEM [the tertiary care hospital of Diabetic Association of Bangladesh (DAB)]. Patients who had other medical complications and who were unable to answer short list of simple questions were excluded from the study. The knowledge, attitude and practice of the sub-
Correspondence: Farzana Saleh, 125/1 Darussalam Mirpur Dhaka-1216, Bangladesh. Tel: +8801738085007

E-mail: farzanasaleh_sumona@yahoo.com

Key words: knowledge, attitude, practice, type 2 diabetes, obesity.

Acknowledgments: the authors would like to thank IPICS and Diabetic Association of Bangladesh. The authors would also thank the type 2 diabetic subjects who participated in the study. We express our sincere thanks to Farzana Rahman of National College of Home Economics and Sarah Tasmeen, Rajashree Das, Israt Jahan for helping in data collection.

Contributions: FS, research conception and design; FS, SJM, FA, data analysis and interpretation; article drafting, revising and final approval; LA, supervision of research conception and design, data analysis and interpretation; article drafting, revising and final approval; SH, KRA, data acquisition and interpretation; article drafting and final approval.

Conflict of interest: the authors report no conflicts of interest.

Received for publication: 27 June 2011.

Revision received: 27 June 2011.

Accepted for publication: 15 January 2012.

This work is licensed under a Creative Commons Attribution NonCommercial 3.0 License (CC BYNC 3.0).

@C Copyright F. Saleh et al., 2011

Licensee PAGEPress, Italy

Journal of Public Health in Africa 2012; 3:e8

doi:10.4081/jphia.2012.e8

jects were assessed by an interviewer-administered questionnaire. A standard questionnaire was constructed in local language and interview was administrated in OPD setting. A medium sized four-part questionnaire was designed by the researcher. The first part of the questionnaire consisted of socio-demographic information, family history of diabetes and obesity, diet prescribed. Part two covered knowledge about obesity, methods of weight measurement, steps to control obesity, good and bad lipids, ideal body weight, healthy foods, energy requirement for maintaining ideal body weight and benefits of exercise. Part three of the questionnaire assessed the attitude of the respondents towards lifestyle characteristics such as diet, physical activity, ideal body weight and calorie intake. Part four focused on steps taken to prevent obesity, weight management, calorie and food intake and physical activity. There were 15 knowledge, 14 attitude and 6 practice questions and for each acceptable questions 1 mark was given and 0 for wrong answer. For each respon- 
dent a sum score was calculated to define knowledge and practice variable. Three point Likert scale was used to assess attitude on various items. ${ }^{11}$ Body weight and height was measured by using appropriate tools. BMI criteria for Asian population were used to identify overweight and obese of the respondents. ${ }^{12}$ The data analysis was done by using the Statistical Package for Social Science (SPSS) computer program version 11.5 (SPSS Inc., Chicago, IL, USA). All P-values presented are two-tailed. The statistical tests were considered significant at a level of $\leq 5 \%(\leq 0.05)$. Ethical approval was obtained from the DAB ethical and research review committee. Informed written consent was taken from all respondents after full explanation of the nature, purpose and all procedures used for the study. Confidentiality of participants was maintained at all times.

\section{Results}

Table 1 shows the characteristics of the respondents. Mean age of the study respondents were $45.17 \pm 5.68$ years and among them $45 \%$ were male. About $8 \%$ were illiterate, $38 \%$ had primary education, $34 \%$ had secondary or higher secondary education and $20 \%$ had graduation and above degree. The mean percentage of knowledge, attitude and practice score of the respondents was [mean \pm SD (\%)] $60.03 \pm 13.82,79.30 \pm 8.27$ and $55.50 \pm 19.21$ respectively. Table 2 shows the BMI of the

Table 1. Characteristics of the study subjects $(n=160)$.

\begin{tabular}{ll} 
Parameters & \\
Age, years & $45.17 \pm 5.68$ \\
Sex & $72(45 \%)$ \\
$\quad$ Male & $88(55 \%)$ \\
Female & $13(8 \%)$ \\
\hline Education & $61(38 \%)$ \\
Illiterate & $54(34 \%)$ \\
$\quad$ Primary & $32(20 \%)$ \\
Secondary-higher secondary & \\
Graduate and above & $45(28 \%)$ \\
Occupation & $78(49 \%)$ \\
Service & $37(23 \%)$ \\
Housewife & \\
Others & \\
(labor/ unemployed) & 120,000 \\
Income & $(14,400-$ \\
Yearly income (BDT)* & $3,240,000)$ \\
& \\
& $60.03 \pm 13.82$ \\
KAP score & $79.30 \pm 8.27$ \\
Knowledge score (\%) & $55.50 \pm 19.21$ \\
Attitude score (\%) & \\
Practice score (\%) & \\
\hline Results are expressed number (\%), mean $\pm S D$ and median (range); \\
*1us\$=70 BDT.
\end{tabular}

respondents according to sex. In this study, BMI $\left(\mathrm{kg} / \mathrm{m}^{2}, \mathrm{M} \pm \mathrm{SD}\right)$ of the respondents were $25.6 \pm 4$. Among them $25 \%$ belongs to normal weight, half of them were overweight and rest of were obese.

Table 3 shows the knowledge regarding obesity among the study subjects. Majority of the respondents (99\%) did not have any idea about the meaning of obesity. More than half of the respondents could not give the answer about the normal blood glucose level (59\%) and ideal body weight (59\%). Majority of the respondents $(88 \%)$ had no idea about their own energy requirement and $19 \%$ did not know about the methods of weight measurement. Nearly half of the respondents knew about the good

lipids for health (Table 3). Knowledge about few commonly consumed fast food and fiber rich foods were assessed. Majority of the respondents stated that fast foods (77\%), soft drinks (84\%) and mayonnaise (33\%) were not bad for weight management. On the other hand, most of the respondents (97\%) said fiber rich food is good for health. Majority of them gave correct answer about red meat (93\%), egg yolk (89\%), butter, cheese and cream (91\%).

Table 4 shows the attitude regarding obesity among the study subjects. Majority of the respondents agreed on the positive statement on willingness to follow proper diet and maintaining ideal body weight (92\%), while $87 \%$ of them agreed that it is necessary to know ener-

Table 2. Body mass index of the study subjects $(n=160)$.

\begin{tabular}{lcccc} 
Measurement & Total $(\mathrm{n}=160)$ & $\begin{array}{c}\text { Male } \\
(\mathrm{n}=72)\end{array}$ & $\begin{array}{c}\text { Female } \\
(\mathrm{n}=88)\end{array}$ & $\mathrm{P}$ \\
BMI $\left(\mathrm{kg} / \mathrm{m}^{2}\right)$ & $25.6 \pm 3.73$ & $24.3 \pm 3.07$ & $26.8 \pm 3.87$ & 0.0001 \\
Normal $(18.5-22.9)$ & $40(25 \%)$ & $28(39 \%)$ & $12(14 \%)$ & \\
\hline Overweight $(23-27.5)$ & $80(50 \%)$ & $34(47 \%)$ & $46(52 \%)$ & \\
Obese $(>27.5)$ & $40(25 \%)$ & $10(14 \%)$ & $30(34 \%)$ & \\
\hline
\end{tabular}

Results are expressed as mean \pm SD and number (\%); BMI, body mass index.

Table 3. Knowledge regarding obesity among the study subjects $(n=160)$.

\begin{tabular}{lccc} 
Knowledge & $\begin{array}{c}\text { Correct } \\
\text { answer }\end{array}$ & $\begin{array}{r}\text { Wrong } \\
\text { answer }\end{array}$ & $\begin{array}{c}\text { Don't } \\
\text { know }\end{array}$ \\
Understanding meaning of obesity & $0(0 \%)$ & $1(1 \%)$ & $159(99 \%)$ \\
Normal blood glucose level & $56(35 \%)$ & $9(7 \%)$ & $95(59 \%)$ \\
\hline Ideal body weight & $57(36 \%)$ & $8(5 \%)$ & $95(59 \%)$ \\
Energy requirement for maintaining ideal body weight & $17(11 \%)$ & $2(1 \%)$ & $141(88 \%)$ \\
\hline Method of weight measurement & $62(39 \%)$ & $58(43 \%)$ & $30(19 \%)$ \\
Good lipid for health & $79(49 \%)$ & $1(1 \%)$ & $80(50 \%)$ \\
\hline Knowledge about preference for: & & & \\
$\quad$ Mayonnaise & $0(0 \%)$ & $52(33 \%)$ & $108(68 \%)$ \\
Soft drinks & $0(0 \%)$ & $134(84 \%)$ & $26(16 \%)$ \\
Fast foods (burger, deep fried foods, pizza, hot dog, etc.) & $123(77 \%)$ & $37(23 \%)$ \\
Red meat & $149(93 \%)$ & $1(1 \%)$ & $10(6 \%)$ \\
Egg yolk & $149(91 \%)$ & $3(2 \%)$ & $15(9 \%)$ \\
Butter, cheese and cream & $3(2 \%)$ & $11(7 \%)$ \\
Fiber rich foods & $153(97 \%)$ & $0(0 \%)$ & $7(4 \%)$ \\
\hline
\end{tabular}

Results are expressed as number (\%).

Table 4. Attitude regarding obesity among the study subjects $(n=160)$.

\begin{tabular}{|c|c|c|c|}
\hline Attitude statements & $\begin{array}{l}\text { Positive } \\
\text { N (\%) }\end{array}$ & $\begin{array}{l}\text { Undecided } \\
\text { N (\%) }\end{array}$ & $\begin{array}{l}\text { Negative } \\
\text { N (\%) }\end{array}$ \\
\hline Prevention of obesity by dietary management & $157(98)$ & $1(1)$ & $2(1)$ \\
\hline Prevention of obesity by exercise & $155(97)$ & $3(2)$ & $2(1)$ \\
\hline Willing to follow proper diet & $148(92)$ & $9(6)$ & $3(2)$ \\
\hline Willing to exercise & $157(98)$ & $3(2)$ & $0(0)$ \\
\hline $\begin{array}{l}\text { Awareness about obesity among family members } \\
\text { of diabetic person }\end{array}$ & $150(94)$ & $8(5)$ & $2(1)$ \\
\hline $\begin{array}{l}\text { Necessary to follow energy requirement } \\
\text { for maintaining ideal body weight }\end{array}$ & 139 (87) & $5(3)$ & $16(10)$ \\
\hline Essential to maintain ideal body weight & $147(92)$ & $7(4)$ & $6(4)$ \\
\hline
\end{tabular}

Results are expressed as number (\%). 
gy requirement for maintaining ideal body weight. Almost all respondents showed positive attitude towards prevention of obesity by dietary management (98\%), exercise (97\%) and willingness to exercise (98\%). About 90\% showed positive attitude that family members of a diabetic patient should aware regarding obesity.

Figures 1 and 2 show the practice of the respondents to maintain ideal body weight and duration of exercise according to their BMI. More than half of the normal weight and overweight respondents did exercise $>45 \mathrm{~min}$, while about one third obese respondents did not do exercise (35\%).

Table 5 shows the knowledge, attitude and practice score of the study subjects according to different socio-demographic and anthropometric variables. The knowledge and attitude scores (\%) did not differ between male and female but the practice score (\%) of male was significantly higher compared to female $(60.45 \pm 14.09$ vs $51.46 \pm 21.81, \mathrm{P}<0.002)$. No influence of occupation was found on knowledge score (\%) $(\mathrm{P}=0.21)$ and attitude score (\%) $(\mathrm{P}=0.33)$. However, occupation had significant influence on practice group $(\mathrm{P}=0.003)$ and those who were in service showed better practice. Knowledge, attitude and practice score were significantly associated with respondents' level of education $(\mathrm{P}=0.0001$, $\mathrm{P}=0.007$ and $\mathrm{P}=0.05$ respectively). Knowledge and attitude score (\%) did not differ significantly among the BMI group, while practice score (\%) differ significantly among the BMI groups $(\mathrm{P}=0.0001)$.

\section{Discussion}

Obesity is one of the challenges in the prevention and management of diabetes. As patients are the most important decision makers, they should receive enough instruction to make informed decisions about prevention and management. ${ }^{9}$ Education can be more effective when it is educated according to knowledge, attitude and practice of patients. However, there is surprisingly little data on KAP of diabetic patients regarding obesity. In the present study the mean values of knowledge and practice score were found average but attitude score was encouraging. It is noticeable that majority of the respondents were unaware about ideal body weight, energy requirement or even the weight measurement technique. Moreover, participants were asked about some foods whether they are healthier or not and majority of them considered fast food, soft drinks, mayonnaise as healthier food. Such eating preferences go a long way in the development and propagation of overweight and obesity among patients and evi-
Table 5. Knowledge, attitude and practice score of the study subjects according to different socio demographic and anthropometric variables.

\begin{tabular}{|c|c|c|c|}
\hline $\begin{array}{l}\text { Variables } \\
(\%)\end{array}$ & $\begin{array}{c}\text { Knowledge score } \\
(\%)\end{array}$ & Attitude score & $\begin{array}{c}\text { Practice score } \\
(\%)\end{array}$ \\
\hline $\begin{array}{l}\text { Sex } \\
\quad \text { Male }(\mathrm{n}=72) \\
\text { Female }(\mathrm{n}=88) \\
\text { P value }\end{array}$ & $\begin{array}{c}59.56 \pm 13.35 \\
60.41 \pm 14.25 \\
0.701\end{array}$ & $\begin{array}{c}79.34 \pm 7.97 \\
79.26 \pm 14.25 \\
0.59\end{array}$ & $\begin{array}{c}59.56 \pm 13.35 \\
60.41 \pm 14.25 \\
0.0001\end{array}$ \\
\hline $\begin{array}{l}\text { Education } \\
\text { Illiterate } \\
\text { Primary } \\
\text { Secondary-higher secondary } \\
\text { Graduate and above } \\
\text { Pvalue }\end{array}$ & $\begin{array}{l}46.49 \pm 20.82 \\
54.72 \pm 11.60 \\
62.42 \pm 10.08 \\
71.57 \pm 9.85 \\
0.0001\end{array}$ & $\begin{array}{l}77.64 \pm 9.47 \\
78.79 \pm 11.60 \\
62.42 \pm 10.08 \\
71.57 \pm 9.85 \\
\quad 0.007\end{array}$ & $\begin{array}{l}42.93 \pm 18.13 \\
57.22 \pm 17.46 \\
54.15 \pm 20.53 \\
59.61 \pm 19.03 \\
0.05\end{array}$ \\
\hline $\begin{array}{l}\text { Occupation } \\
\text { Service } \\
\text { Housewife } \\
\text { Others (laborer/ unemployed) } \\
\text { P value }\end{array}$ & $\begin{array}{c}62.58 \pm 14.13 \\
59.89 \pm 13.57 \\
57.18 \pm 13.72 \\
0.21\end{array}$ & $\begin{array}{c}80.75 \pm 7.31 \\
79.03 \pm 8.58 \\
78.12 \pm 8.67 \\
0.33\end{array}$ & $\begin{array}{c}61.94 \pm 13.12 \\
50.47 \pm 21.64 \\
58.30 \pm 17.40 \\
0.003\end{array}$ \\
\hline $\begin{array}{l}\text { BMI } \\
\text { Normal (18.5-22.9) } \\
\text { Overweight }(23-27.5) \\
\text { Obese (>27.5) } \\
\text { Pvalue }\end{array}$ & $\begin{array}{c}59.21 \pm 13.95 \\
60.52 \pm 14.33 \\
59.85 \pm 12.90 \\
0.87\end{array}$ & $\begin{array}{c}80.94 \pm 5.31 \\
78.98 \pm 8.96 \\
78.29 \pm 9.16 \\
0.32\end{array}$ & $\begin{array}{c}64.37 \pm 12.52 \\
58.34 \pm 17.20 \\
41.96 \pm 20.06 \\
0.0001\end{array}$ \\
\hline
\end{tabular}

Results are expressed as mean \pm SD, $P<0.05$ are taken as level of significance; $B M I$, body mass index.

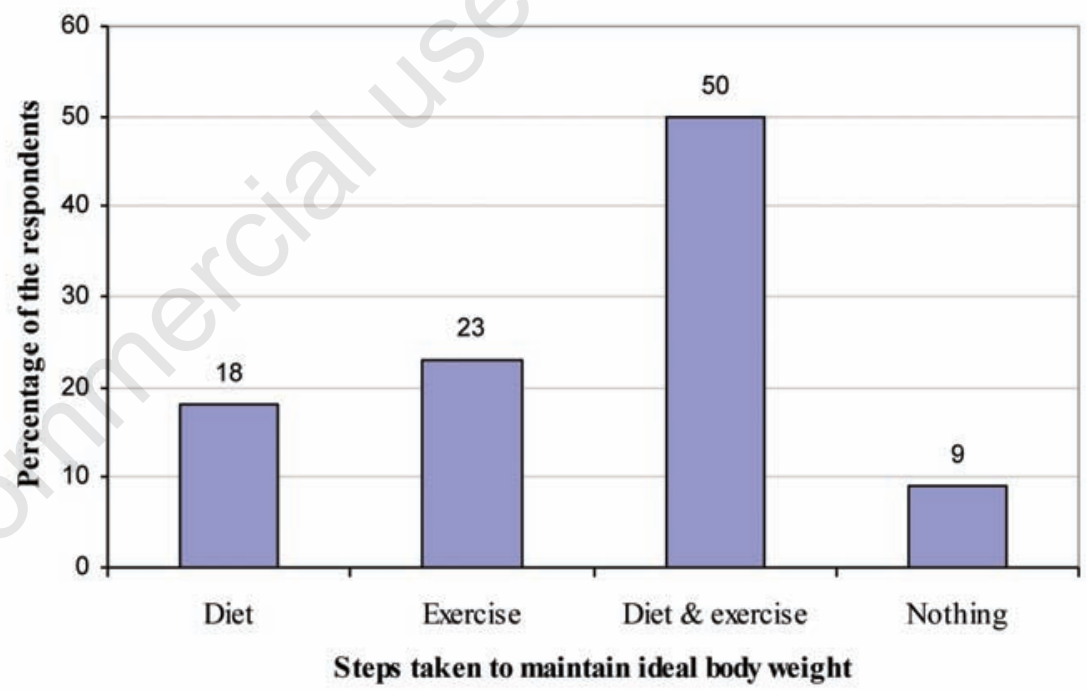

Figure 1. Practice of the respondents to maintain ideal body weight.

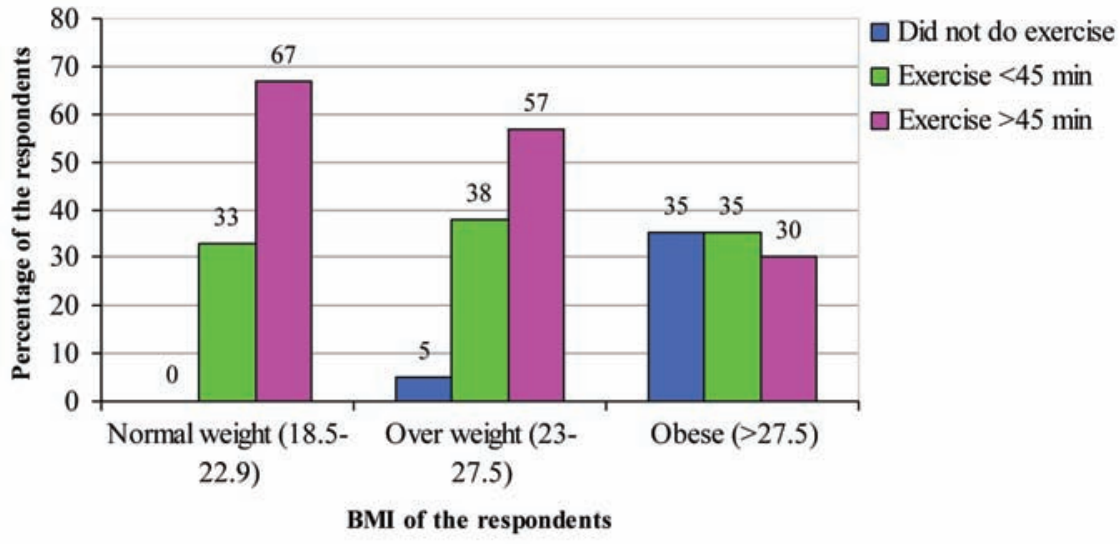

Figure 2. Exercise time of the respondents according to their body mass index. 
dence suggests that reduction in the intake of fat and sugar lead to body weight control and prevent overweight and obesity. ${ }^{13}$ Similar study conducted in Karachi, Pakistan also showed that a large proportion of participants preferred oily and fried foods. ${ }^{14}$ The need for education about these areas is required. The lack of proper knowledge as regards diet requirements of each patient should be given individual dietary advice with clear view of its purpose, so that they can understand and follow it in practice. ${ }^{15}$ On the other hand, majority of the participants of present study had good knowledge regarding weight-reducing diet which contains fruits, vegetables and fiber. If such knowledge could be transformed into practice then body weight control could be an achievable target.

However, as knowledge alone is insufficient: Lockington et al. ${ }^{16}$ proposed other factors such as attitude and motivation are also important. In this study most of the respondents showed positive attitude towards maintaining ideal body weight and preventing or controlling obesity by dietary management and exercise. But it is demonstrated that this willingness is not transferred to actual practice. Only half of the respondents followed proper diet and exercise and overall exercise also found poor.

It is matter to concern that about threefourth respondents are overweight and obese and among them the proportion of female is higher than male. Although knowledge and attitude score is quite similar but practice score is significantly higher among male than female. However, it is assumed that knowledge affects attitude ${ }^{16}$ and attitude affects practice ${ }^{8,17}$ but it is generally believed that in a developing country like Bangladesh, females are lagging behind compared to males in all spheres of life. Therefore, it is important to identify interventions that can reinforce their practice despite their level of knowledge and attitude of particular area. ${ }^{8}$ Level of education showed significant effect on KAP scores which also supports several studies. ${ }^{9,18,19}$ It was found that literate respondents had higher practice score than illiterate. In this study mean practice score was higher in those who were in service. Another study conducted in Pakistan also showed that mean practice score of housewife and blue-collar worker was lower than white-collar worker's. ${ }^{18}$ It may be due to the accessibility of the information or lack of awareness. Thus this group should be targeted for the intervention. It is quite obviously found that practice score is significantly higher among normal weight group than obese group. Exercise time of the study subjects gradually decreased according to their BMI. It has been shown that reduced level of physical activity play a predominant role in the development of obesity. ${ }^{20}$ Improving knowledge of the patient can improve their attitude and in long run change their practices to embrace healthier lifestyles such as following healthy diet and engaging in physical activity. Such practices will delay the onset of further complications in those who are diabetic.

As this study was conducted in a single hospital, the result maybe not giving the true reflection of the general population. Moreover, the study conducted in a urban hospital where education may be readily accessible, raises further concern as there is more likelihood that the majority of people, especially those living in rural areas and having less access to information, might have even poorer perception and practices.

Therefore, there is a need for increased effort towards developing and making education programs focusing on empowering the persons with diabetes, not only to provide them information but also the ability and empowerment to change knowledge and attitude into practice. It is hoped that these findings have major implications for the design of patient education program.

\section{References}

1. Jafar TH, Chaturvedi N, Pappas G. Prevalence of overweight and obesity and their association with hypertension and diabetes mellitus in an Indo-Asian population. CMAJ 2006;175:1071-77.

2. Rahman MM, Rahim MA, Nahar Q. Prevalence and risk factors of type 2 diabetes in an urbanizing rural community of Bangladesh. Bangladesh Med Res Counc Bull 2007;33:48-54.

3. Mokdad AH, Ford ES, Bowman BA, et al. Prevalence of obesity, diabetes, and obesity-related health risk factors, 2001. JAMA 2003;289:76-9.

4. Rahim MA, Hussain A, Azad Khan AK, et al. Rising prevalence of type 2 diabetes in rural Bangladesh: a population based study. Diabetes Res Clin Pract 2007;77: 300-5.

5. Ahmed KR, Akhter A, Pervin T, et al. Knowledge, attitude and practice of hypercholesterolemic type 2 diabetic subjects on dyslipidemia. Diabetologia 2004;47:A953.

6. Rahman MM, Rahim MA, Nahar Q. Prevalence and risk factors of Type 2 diabetes in an urbanizing rural community of Bangladesh. Bangladesh Med Res Counc Bull 2007;33:48-54.

7. Hossain P, Kawar B, Nahas ME. Obesity and Diabetes in the Developing World - A Growing Challenge. N Engl J Med 2007; 356:213-15.

8. Maina WK, Ndegwa ZM, Njenga EW, Muchemi EW. Knowledge, attitude and practices related to diabetes among community members in four provinces in Kenya: a cross-sectional study. Pan Afr Med J 2010;7:2.

9. Murata GH, Shah JH, Adam KD, et al. Factors affecting diabetes knowledge in type 2 diabetic veterans. Diabetologia 2003;46:1170-78.

10. Connoly V, Unwin N, Sherriff P, et al. Diabetes prevalence and socioeconomic status: a population based study showing increased prevalence of type 2 diabetes mellitus in deprived areas. J Epidemiol Community Health 2000;54:173-77.

11. Likert R. A Technique for the measurement of attitudes. Arch Psychol 1932; 140:5-53.

12. WHO Expert Consultation. Appropriate body-mass index for Asian populations and its implications for policy and intervention strategies. Lancet 2004;363:157-63.

13. Saris WH. Sugars, energy metabolism and body weight control. Am J Clin Nutr 2003;78:850-57.

14. Qidwai W, Azam SI. Knowledge, attitude and practice regarding obesity among patients, at Aga Khan University Hospital, Karachi. J Ayub Med Coll Abbottabad 2004;16:32-4.

15. Badruddin N, Basit A, Hydrie MZI, Hakeem R. Knowledge, attitude and practice visiting a diabetes care unit. Pak J Nutrition 2002;1:99-102.

16. Ambigapathy R, Ambigapathy S, Ling HM. A knowledge, attitude and practice (KAP) study of diabetes mellitus among patients attending Klinik Kesihatan Seri Manjung. NCD Malaysia 2003;2:6-15.

17. Saleh F, Ahmed KR, Rashid IB, et al. Evaluation of the levels of knowledge, attitude and practices of Bangladeshi type 2 diabetic subjects. Diab Endo J 2005;33:24.

18. Rafique G, Azam SI, White F. Diabetes knowledge, beliefs and practices among people with diabetes attending a university hospital in Karchi, Pakistan. East Mediterr Health J 2006;12:590-98.

19. Rani PK, Raman R, Subramani S, et al. Knowledge of diabetes and diabetic retinopathy among rural populations in India, and the influence of knowledge of diabetic retinopathy on attitude and practice. Rural Remote Health 2008;8:838.

20. Webber J. Energy balance in obesity. Proc Nutr Soc 2003;62:539-43. 